\title{
Understanding protein evolutionary rate by integrating gene co-expression with protein interactions
}

\author{
Kaifang Pang ${ }^{1}$, Chao Cheng ${ }^{2}$, Zhenyu Xuan ${ }^{3}$, Huanye Sheng ${ }^{1 *}$, Xiaotu $\mathrm{Ma}^{3^{*}}$
}

\begin{abstract}
Background: Among the many factors determining protein evolutionary rate, protein-protein interaction degree (PPID) has been intensively investigated in recent years, but its precise effect on protein evolutionary rate is still heavily debated.

Results: We first confirmed that the correlation between protein evolutionary rate and PPID varies considerably across different protein interaction datasets. Specifically, because of the maximal inconsistency between yeast twohybrid and other datasets, we reasoned that the difference in experimental methods contributes to our inability to clearly define how PPID affects protein evolutionary rate. To address this, we integrated protein interaction and gene co-expression data to derive a co-expressed protein-protein interaction degree (ePPID) measure, which reflects the number of partners with which a protein can permanently interact. Thus, irrespective of the experimental method employed, we found that (1) ePPID is a better predictor of protein evolutionary rate than PPID, (2) ePPID is a more robust predictor of protein evolutionary rate than PPID, and (3) the contribution of ePPID to protein evolutionary rate is statistically independent of expression level. Analysis of hub proteins in the Structural Interaction Network further supported ePPID as a better predictor of protein evolutionary rate than the number of distinct binding interfaces and clarified the slower evolution of co-expressed multi-interface hub proteins over that of other hub proteins.
\end{abstract}

Conclusions: Our study firmly established ePPID as a robust predictor of protein evolutionary rate, irrespective of experimental method, and underscored the importance of permanent interactions in shaping the evolutionary outcome.

\section{Background}

Among the many factors determining protein evolutionary rate [1-5], protein-protein interaction degree (PPID), defined as the number of interaction partners a protein has in a protein interaction network, is an important predictor. A negative correlation between protein evolutionary rate and PPID was first reported in [6], which is consistent with the "functional density" hypothesis [7] that protein evolutionary rate is primarily determined by the proportion of residues involved in specific functions.

\footnotetext{
* Correspondence: hysheng@sjtu.edu.cn; xiaotuma@utdallas.edu

${ }^{1}$ Department of Computer Science and Engineering, Shanghai Jiao Tong

University, Shanghai, 200240, China

${ }^{3}$ Department of Molecular and Cell Biology, Center for Systems Biology,

University of Texas at Dallas, Richardson, TX 75080, USA

Full list of author information is available at the end of the article
}

Since then, several differing conclusions have been drawn. The controversies mainly focus on whether the correlation between PPID and protein evolutionary rate (1) is an artefact of biased protein interaction datasets [8-12], (2) is linked to experimental setup that favors counting more interactions for abundant proteins [13-15], or (3) is confounded by other genomic variables $[16,17]$.

The relationship between protein evolutionary rate and PPID is mostly studied through hub proteins, i.e., proteins with a large number of interaction partners, from many different aspects [18-23]. For example, hub proteins can be classified into date and party hubs [24], singlishinterface and multi-interface hubs [22], singlish-iMotif and multi-iMotif hubs [23]. It was found that multi-interface hubs are mostly party hubs and singlish-interface hubs are
C Biomed Central 
mostly date hubs [22]. It was also found that party hubs evolve more slowly than date hubs $[18,20]$ and multi-interface hubs evolve more slowly than singlish-interface hubs [22], but these findings are also challenged $[19,21]$. Furthermore, it was found that multi-iMotif hubs do not evolve more slowly than singlish-iMotif hubs [23]. These lines of evidence suggest a profound lack of consensus about the evolutionary rate differences between different types of hub proteins.

Therefore, in this paper, we first re-investigated the relationship between protein evolutionary rate and protein-protein interaction degree (PPID) and confirmed that the correlation between protein evolutionary rate and PPID varies considerably across different protein interaction datasets. We then integrated protein interaction and gene co-expression data to derive a co-expressed protein-protein interaction degree (ePPID) measure, which reflects the number of partners with which a protein can permanently interact. Our results demonstrated that ePPID is a more robust predictor of protein evolutionary rate than PPID. It was further found that the contribution of ePPID to protein evolutionary rate is statistically independent of expression level. Finally, we established that ePPID could predict protein evolutionary rate better than the number of distinct binding interfaces for hub proteins in the Structural Interaction Network and clarified the slower evolution of co-expressed multiinterface hub proteins over that of other hub proteins.

\section{Results}

\section{Controversial correlations between PPID and protein evolutionary rate}

Researchers have found very different correlations between PPID and protein evolutionary rate [6,8-17]. To address this variation, we first obtained the non-synonymous substitution rate $(\mathrm{dN})$ data on yeast [25] for protein evolutionary rate (see Methods). Next, to account for experimental bias, reliability and completeness [26-32], nine yeast protein interaction datasets were compiled from different sources (see Methods). We analyzed six protein interaction datasets in the main text and the analysis results of the other three were provided in Additional file 1, Text S1. Scatter plots of protein evolutionary rate $\mathrm{dN}$ versus PPID, together with linear regression fit, are shown in the upper panels of Figure 1A-C for the "Y2H-union", "Combined$\mathrm{AP} / \mathrm{MS}$ " and "LC-multiple" datasets, and in the upper panels of Figure 1D-F for the "Updated-HC", "DIP-CORE" and "DIP-FULL" datasets. For the six protein interaction datasets, negative correlation coefficients between PPID and protein evolutionary rate are observed. However, the statistical significance of these correlation coefficients varies considerably across different protein interaction datasets, which is consistent with previous results [6,8-17]. Specifically, significant results are observed for protein interaction datasets that include "Combined-AP/MS", "LC-multiple", "Updated-HC", "DIP-CORE" and "DIPFULL" (Figure 1B-F). The "Combined-AP/MS" and "LC-multiple" datasets were compiled from the affinity purifications followed by the mass spectrometry (AP/MS) method and literature curation, respectively, while the other three datasets were compiled from diverse data sources. On the other hand, an insignificant result is observed for the "Y2H-union" dataset (Figure 1A), which is only compiled from yeast two-hybrid ( $\mathrm{Y} 2 \mathrm{H})$ assays. Moreover, the percent variance of evolutionary rate explained by PPID is also the lowest in the "Y2H-union" dataset (Figure 1 and column 3 of Additional file 1, Table S1). To account for the non-normality of the distribution of PPID, we also computed Spearman rank correlation between PPID and protein evolutionary rate and found that the correlations are highly significant in all the six datasets except "Y2H-union" (column 3 of Table 1). These results suggest that the differing results reached by previous investigators may be related to the difference between $\mathrm{Y} 2 \mathrm{H}$ and other experimental methods, possibly because $\mathrm{Y} 2 \mathrm{H}$ datasets do not have abundance bias and/or are enriched for transient protein interactions [26,32].

We next studied if the protein abundance effect may account for the above significant difference between the Y2 $\mathrm{H}$ and other datasets. We computed Spearman rank correlations between PPID and protein abundance [33] and found that the PPID measure may contain independent information for protein evolutionary rate (see Additional file 1, Text S2). Then, we studied the percentage variance of protein evolutionary rate explained by PPID when protein abundance is controlled for (column 4 of Table 2). As can be seen, considerable percent variances of evolutionary rate explained by PPID remain in all the six protein interaction datasets. In addition, the partial Spearman correlation coefficients between PPID and protein evolutionary rate are still significant (though marginally significant in the "Combined-AP/MS" dataset) after controlling for protein abundance (column 4 of Table 3), with the exception of "Y2H-union" datasets, suggesting that PPID contains independent information for evolutionary rate (similar results were obtained when using other expression-related data [34-36], data not shown). Thus, we next wanted to study how to better understand evolutionary rate by integrating PPID with gene expression data.

\section{Co-expressed protein-protein interaction degree (ePPID) predicts protein evolutionary rate better than PPID}

Proteins with higher PPID are assumed to have a greater proportion of residues involved in interactions and thus evolve more slowly than proteins with lower PPID [6,9]. This may be true for a protein with many permanent interaction partners, because the protein tends to form a 

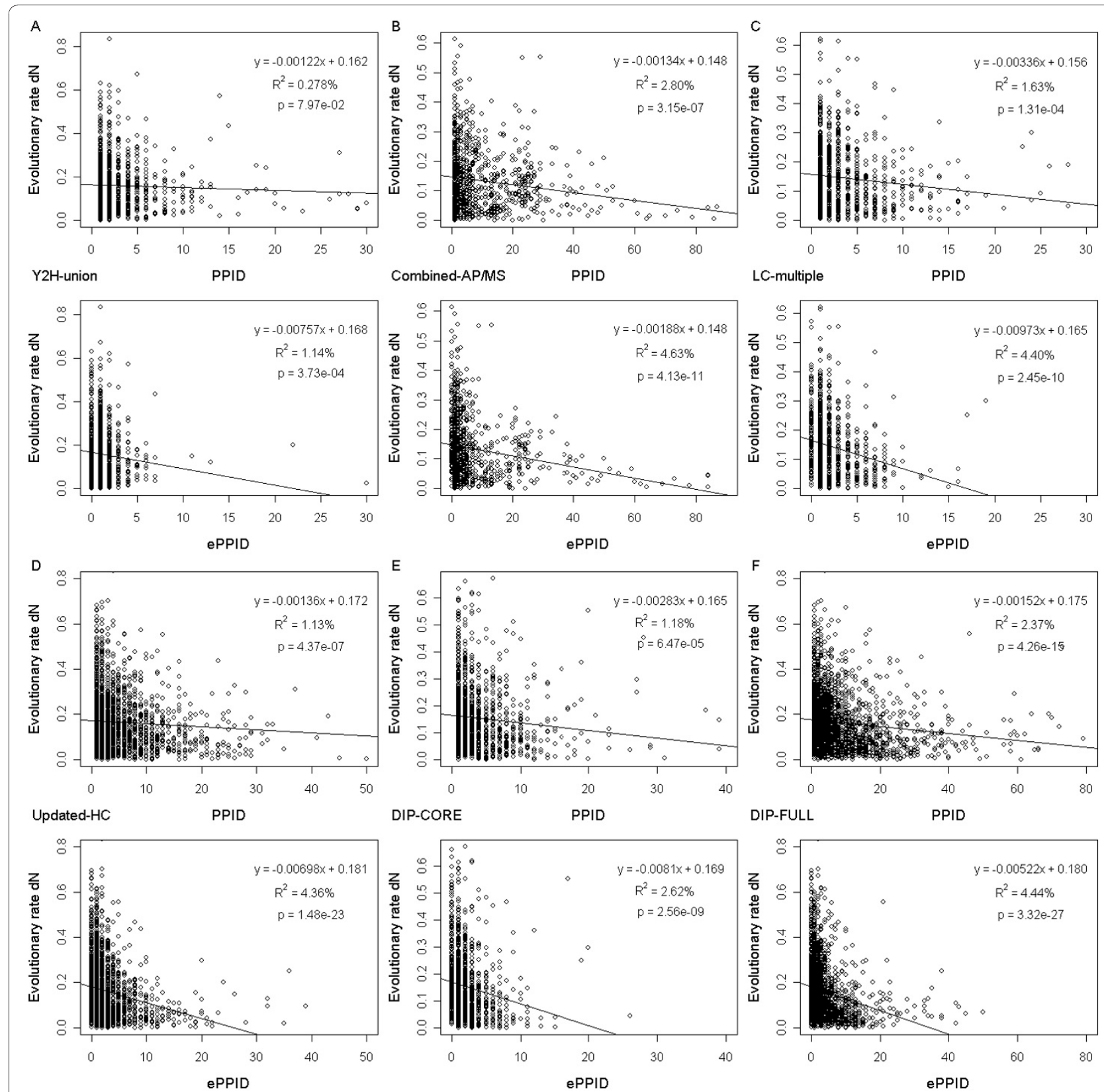

Figure 1 Relationship of protein evolutionary rate dN with PPID and ePPID. Scatter plots of protein evolutionary rate dN versus PPID (upper panel) and ePPID (bottom panel) together with the linear regression fit in the six protein interaction datasets: (A) "Y2H-union" (B) "Combined-AP/MS" (C) "LC-multiple" (D) "Updated-HC" (E) "DIP-CORE" (F) "DIP-FULL".

permanent complex with its partners through multiple distinct binding interfaces and may have a greater proportion of interface residues [22]. However, a protein with many transient interaction partners may transiently interact with its different partners through the same binding interface (though it is possible that the protein may form a transient complex with its partners through multiple distinct binding interfaces), thus the PPID of the protein may not well reflect the proportion of its interface residues [22]. Furthermore, interface residues of permanent interactions are found to evolve more slowly than those of transient interactions $[37,38]$. In other words, permanent interactions are more likely to exert higher selective constrains on protein evolution [18,20,22,37-39] and protein evolutionary rate may be more reflective of the proportion of residues involved in permanent interactions. On the other hand, permanent interactions tend to show significant co-expression 
Table 1 Spearman correlation of PPID, ePPID and betweenness with protein evolutionary rate

\begin{tabular}{lllll}
\hline Protein interaction datasets & $n$ & PPID vs. dN & ePPID vs. dN & betweenness vs. dN \\
\cline { 3 - 5 } & & $r h o(p)$ & $r h o(p)$ & $r h o(p)$ \\
\hline Y2H-union & 1,104 & $-0.0487(1.06 \mathrm{e}-01)$ & $-0.142(2.25 \mathrm{e}-06)$ & $-0.0365(2.26 \mathrm{e}-01)$ \\
\hline Combined-AP/MS & 922 & $-0.158(1.46 \mathrm{e}-06)$ & $-0.251(1.03 \mathrm{e}-14)$ & $-0.241(1.21 \mathrm{e}-13)$ \\
\hline LC-multiple & 894 & $-0.172(2.46 \mathrm{e}-07)$ & $-0.267(4.72 \mathrm{e}-16)$ & $-0.186(2.05 \mathrm{e}-08)$ \\
\hline Updated-HC & 2,245 & $-0.183(2.62 \mathrm{e}-18)$ & $-0.242(2.58 \mathrm{e}-31)$ & $-0.128(1.30 \mathrm{e}-09)$ \\
\hline DIP-CORE & 1,342 & $-0.152(2.33 \mathrm{e}-08)$ & $-0.254(3.69 \mathrm{e}-21)$ & $-0.111(4.53 \mathrm{e}-05)$ \\
\hline DIP-FULL & 2,572 & $-0.233(4.56 \mathrm{e}-33)$ & $-0.271(1.40 \mathrm{e}-44)$ & $-0.188(5.90 \mathrm{e}-22)$ \\
\hline
\end{tabular}

$\mathrm{dN}$ represents protein evolutionary rate measured by non-synonymous substitutions. $n$ is the number of proteins for which both PPID and protein evolutionary rate are available. rho is Spearman rank correlation coefficient, and $p$ is the corresponding statistical significance. Bold indicates that $p$ is significant at the statistical significance level of 0.05 .

$[32,40]$, so we speculate that the number of a protein's co-expressed interaction partners may well reflect the proportion of its residues involved in permanent interactions and thus better predict its evolutionary rate.

Several studies have addressed the difference in selective constraints between permanent and transient interactions on protein evolution [18,20,22,39]. For example, Han et al. [24] used the average Pearson correlation coefficient (APCC) between the expression profiles of a protein and its interaction partners to classify hub proteins into date (with lower APCC score) and party (with higher APCC score) hubs. Date hubs interact with their partners transiently, while party hubs interact with their partners permanently by co-expression. Thus, party hubs have a lower evolutionary rate than date hubs since selective constraints from permanent interactions on party hubs are higher than those from transient interactions on date hubs $[18,20]$. However, there are at least three drawbacks in using APCC scoring to account for transient protein interactions. First, while there was a bimodal distribution of the APCC scores in the "FYI" dataset [24], no clear bimodal distribution was found in the "DIP-CORE" dataset [41-43], a complete lack of bimodality was observed in several larger high- confidence datasets $[19,21]$, and no robust bimodal distribution was found in the Online Predicted Human Interaction Database $[44,45]$. Thus, it is difficult to set the APCC threshold to distinguish party hubs from date hubs. Second, as an average measure, a high variance of Pearson correlation coefficient (PCC) scores between a hub and its interaction partners will make its APCC score less informative. For example, the APCC score of protein A in Figure 2 is 0.22 , and a moderate APCC score cutoff would classify this protein as a date hub, which is clearly not our intention. Third, the APCC score only measures the average co-expression strength between a hub and its interaction partners, rather than the actual number of interaction partners with which the hub significantly co-expresses. For example, the APCC scores of protein A and B in Figure 2 are the same (0.22), but protein $A$ and $B$ have different numbers of significantly co-expressed interaction partners (seven versus three), which is again not our intention. In fact, several real proteins with low APCC score but high number of co-expressed interaction partners are exemplified in Additional file 1, Text S3. Another attempt was made by Kim et al. [22], who used the number of distinct binding interfaces of a hub to filter out transient

Table 2 The variance of protein evolutionary rate explained by PPID and ePPID when controlling for protein abundance

\begin{tabular}{|c|c|c|c|c|c|}
\hline \multirow[t]{2}{*}{ Protein interaction datasets } & \multirow[t]{2}{*}{$n$} & \multicolumn{4}{|c|}{ Percent variance explained in $\mathrm{dN}$} \\
\hline & & $\operatorname{PPID}(p)$ & $\begin{array}{l}\text { PPID control for } \\
\text { Log(abundance })(p)\end{array}$ & $\operatorname{ePPID}(p)$ & $\begin{array}{l}\text { ePPID control for } \\
\text { Log(abundance })(p)\end{array}$ \\
\hline Y2H-union & 793 & $0.110(3.52 \mathrm{e}-01)$ & $0.145(2.84 \mathrm{e}-01)$ & $0.659(2.22 \mathrm{e}-02)$ & $0.547(3.73 e-02)$ \\
\hline Combined-AP/MS & 763 & $2.50(1.13 e-05)$ & $0.906(8.52 e-03)$ & $4.25(9.08 \mathrm{e}-09)$ & $0.999(5.73 e-03)$ \\
\hline LC-multiple & 680 & $1.29(3.01 \mathrm{e}-03)$ & $1.17(4.72 \mathrm{e}-03)$ & $4.11(9.62 \mathrm{e}-08)$ & $1.70(6.59 \mathrm{e}-04)$ \\
\hline Updated-HC & 1,587 & $0.722(7.04 \mathrm{e}-04)$ & $0.547(3.19 \mathrm{e}-03)$ & $3.53(4.39 e-14)$ & $1.32(4.60 \mathrm{e}-06)$ \\
\hline DIP-CORE & 968 & $0.308(8.42 \mathrm{e}-02)$ & $0.109(3.05 e-01)$ & $1.27(4.44 \mathrm{e}-04)$ & $0.109(3.05 e-01)$ \\
\hline DIP-FULL & 1,792 & $1.99(2.03 e-09)$ & $0.996(2.32 \mathrm{e}-05)$ & $3.99(1.39 e-17)$ & $1.36(7.21 e-07)$ \\
\hline
\end{tabular}

$\mathrm{dN}$ represents protein evolutionary rate measured by non-synonymous substitutions. $n$ is the number of proteins for which PPID, protein evolutionary rate and abundance data are all available. $p$ in column 3 and 5 is the statistical significance of the linear regression of protein evolutionary rate against PPID and ePPID, respectively. $p$ in column 4 and 6 is the statistical significance of the linear regression of protein evolutionary rate against PPID and ePPID when controlling for protein abundance, respectively. Bold indicates that $p$ is significant at the statistical significance level of 0.05 . 
Table 3 Spearman correlation and partial Spearman correlation of PPID and ePPID with protein evolutionary rate.

\begin{tabular}{llllll}
\hline Protein interaction datasets & $n$ & PPID vs. dN & $\begin{array}{l}\text { PPID vs. dN } \\
\text { control for abundance }\end{array}$ & ePPID vs. dN & $\begin{array}{l}\text { ePPID vs. dN } \\
\text { control for abundance }\end{array}$ \\
\cline { 2 - 6 } & & $r h o(p)$ & $r h o(p)$ & $r h o(p)$ & $r h o(p)$ \\
\hline Y2H-union & 793 & $-0.0249(4.85 \mathrm{e}-01)$ & $-0.0260(4.64 \mathrm{e}-01)$ & $-0.116(1.06 \mathrm{e}-03)$ & $-0.0930(8.66 \mathrm{e}-03)$ \\
\hline Combined-AP/MS & 763 & $-0.135(1.85 \mathrm{e}-04)$ & $-0.0666(6.59 \mathrm{e}-02)$ & $-0.229(1.51 \mathrm{e}-10)$ & $-0.103(4.35 \mathrm{e}-03)$ \\
\hline LC-multiple & 680 & $-0.149(9.75 \mathrm{e}-05)$ & $-0.134(4.16 \mathrm{e}-04)$ & $-0.260(6.16 \mathrm{e}-12)$ & $-0.179(2.14 \mathrm{e}-06)$ \\
\hline Updated-HC & 1,587 & $-0.140(2.27 \mathrm{e}-08)$ & $-0.0992(7.24 \mathrm{e}-05)$ & $-0.208(5.21 \mathrm{e}-17)$ & $-0.121(1.14 \mathrm{e}-06)$ \\
\hline DIP-CORE & 968 & $-0.108(7.72 \mathrm{e}-04)$ & $-0.0679(3.45 \mathrm{e}-02)$ & $-0.214(1.72 \mathrm{e}-11)$ & $-0.110(5.65 \mathrm{e}-04)$ \\
\hline DIP-FULL & 1,792 & $-0.223(1.24 \mathrm{e}-21)$ & $-0.162(3.31 \mathrm{e}-12)$ & $-0.252(2.77 \mathrm{e}-27)$ & $-0.156(2.69 \mathrm{e}-11)$
\end{tabular}

$\mathrm{dN}$ represents protein evolutionary rate measured by non-synonymous substitutions. $n$ is the number of proteins for which PPID, protein evolutionary rate and abundance data are all available. rho is Spearman rank correlation coefficient, and $p$ is the corresponding statistical significance. Bold indicates that $p$ is significant at the statistical significance level of 0.05 .

protein interactions. However, since protein structure data are limited, it is impossible to project all structural information onto protein interaction datasets, and, as a result, the number of distinct binding interfaces of a hub may be underestimated. Furthermore, they did not clearly distinguish permanent interfaces from transient interfaces. For example, although a multi-interface hub is more likely to form a permanent complex with its partners through permanent interfaces, it does not rule out the possibility that the multi-interface hub forms a transient complex with its partners through transient interfaces. For another example, the number of distinct binding interfaces of a protein only implies the total number of partners with which it can potentially interact. In nature, however, it is possible that a multi-interface hub transiently interacts with its individual partner through the corresponding binding interface at different spatial-temporal conditions.

Therefore, we proposed a co-expressed protein-protein interaction degree (ePPID), defined as the maximal number of co-expressed interaction partners of a given protein in all gene expression datasets we used (in fact, other variations of such definition yield similar results, see Additional file 1, Text S4), to estimate the number of partners with which a protein can permanently interact (see Methods). It can be seen from the bottom panels of Figure 1A-C and Figure 1D-F that the ePPID measure has statistically significant negative correlation coefficients with protein evolutionary rate across all protein interaction datasets we studied. As shown in Table 1 (column 4 versus column 3), it is clear that the statistical significance obtained by ePPID is better than that
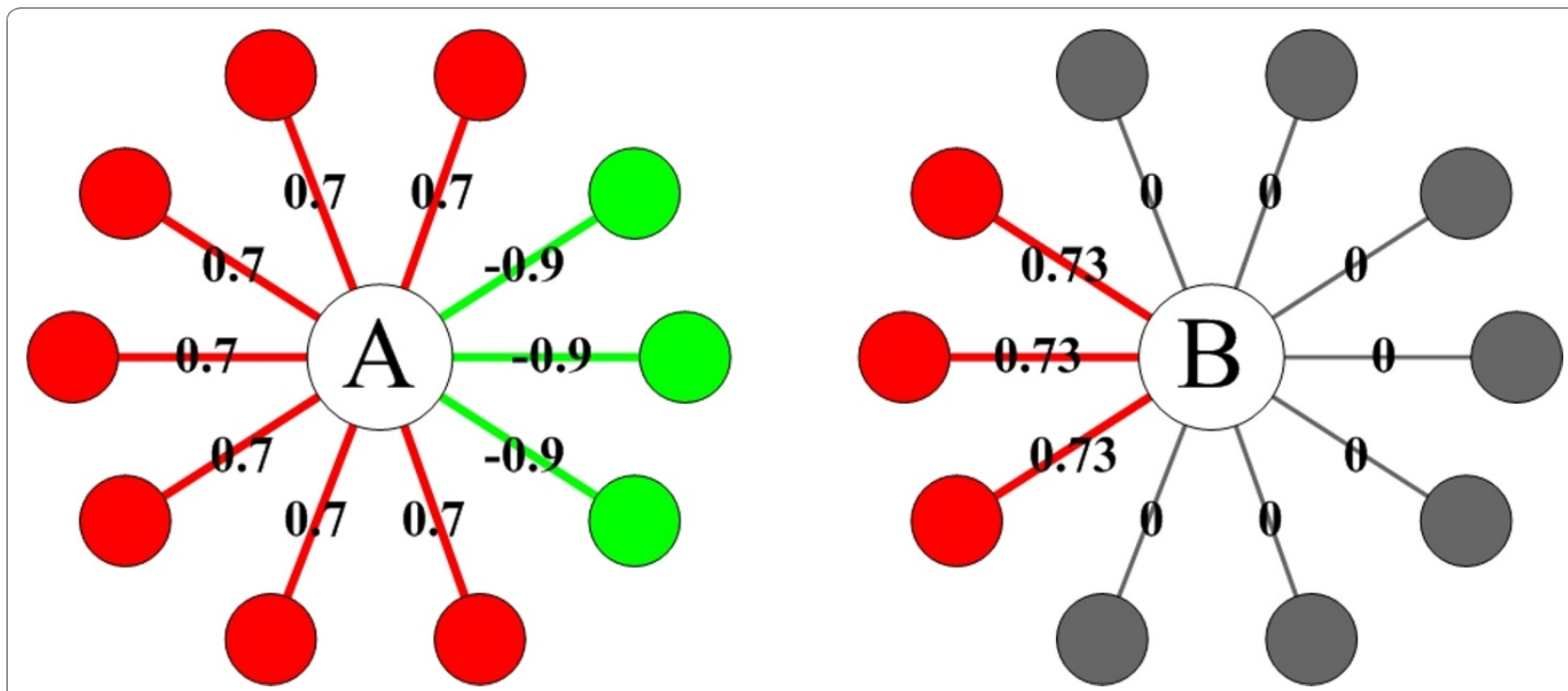

Figure 2 Difference between ePPID and APCC measures. Two hypothetical proteins with the same APCC sCore $((0.7 \times 7-0.9 \times 3) \div 10=$ 0.22 for protein $A$ and $(0.73 \times 3+0 \times 7) \div 10=0.22$ for protein B) but different numbers of significantly co-expressed interaction partners, thus differing ePPID (see the main text for details) scores (seven versus three). Significantly highly co-expressed interactions are indicated using red, while non-co-expressed and highly anti-co-expressed interactions are indicated using gray and green, respectively. 
obtained by PPID. Accordingly, across all protein interaction datasets, ePPID explains a higher percentage variance of protein evolutionary rate than PPID (Figure 1 and Additional file 1, Table S1). These results indicate that ePPID is a better predictor of protein evolutionary rate than PPID. In addition, our further analysis indicated that ePPID predicts evolutionary rate better than betweenness [46-48], another network centrality measure (the last column of Table 1).

We then found that Spearman rank correlations between ePPID and protein abundance are all statistically significant (see Additional file 1, Text S2), suggesting that protein abundance might be a confounding factor for the high correlations between ePPID and protein evolutionary rate. To address this question, we studied the percentage variance of protein evolutionary rate explained by ePPID when protein abundance is controlled for (the last column of Table 2). As can be seen, considerable percent variances of evolutionary rate explained by ePPID remain in all the six protein interaction datasets, with the exception of "DIP-CORE". In addition, partial Spearman correlation coefficient and corresponding statistical significance between ePPID and evolutionary rate (by controlling for protein abundance; the last column of Table 3) are reduced as compared to the original correlations (column 5 of Table 3 ) in all protein interaction datasets. However, the fact that these partial correlations all remain highly significant (the last column of Table 3) also suggests that ePPID makes an independent contribution to protein evolutionary rate. Moreover, with the exception of the "DIP-FULL" dataset, the partial correlations between ePPID and protein evolutionary rate are more significant than those between PPID and protein evolutionary rate after controlling for protein abundance (Table 3, the last column versus column 4), further indicating that ePPID is a better predictor of protein evolutionary rate than PPID. In fact, similar results (Additional file 1, Table S2 and S3) were found using three other protein evolutionary rate data (corresponding to different out-group controls, including S.cer vs S.par, S.cer vs $S$. mik and S.cer vs S.bay, see [49] for details). Mechanistically, we believe that permanent interactions impose more selective pressure on protein evolution than transient interactions, and protein evolutionary rate is more reflective of the number of a protein's permanent interaction partners as measured by ePPID.

\section{The effect of transient interactions on predicting protein evolutionary rate}

With the co-expression information, our ePPID measure can filter out many transient interactions. Thus, we next wanted to study why removing transient protein interactions improved the correlation. In the "Y2Hunion" dataset, we noticed that ePPID explains more than four times the variance of evolutionary rate than does PPID; however, in other datasets, the improvements are generally less than three times (Additional file 1, Table S1). This result suggests that ePPID has filtered out many transient protein interactions in the "Y2H-union" dataset, which may be the reason of lower percent variance of evolutionary rate explained by PPID. On the other hand, improvements are less dramatic in other datasets because transient protein interactions are less enriched. Consistent with this notion, our study on non-co-expressed protein interactions (see Additional file 1, Text S5 for details) suggested that transient interactions are most enriched in the "Y2H-union" dataset (46.1\%) while least enriched in the "Combined-AP/MS" dataset (14.4\%, column 4 of Additional file 1 Table S4), which is also consistent with the fact that transient protein interactions are less co-expressed than permanent co-complex associations [32]. In addition, the number of transient interaction partners of a protein even appears to be positively correlated with protein evolutionary rate (see Additional file 1, Text S5).

Since the "Y2H-union" dataset is enriched for transient physical interactions, ePPID in this dataset mainly filters out a protein's transient physical interactions and thus reflects the number of the protein's permanent physical interactions. In the "Combined-AP/MS" dataset which is enriched for permanent co-complex associations, ePPID mainly filters out a protein's transient cocomplex associations and thus reflects the number of the protein's permanent co-complex associations. In the "Combined-AP/MS" dataset, ePPID may be overestimated due to indirect non-physical interactions (cocomplex associations). Despite this effect, permanent interactions do place higher selective constrains on protein evolution than transient interactions do, further illustrating why our ePPID measure could better predict protein evolutionary rate.

However, the variance of protein evolutionary rate explained by ePPID is still the lowest in the "Y2Hunion" dataset, which may be explained in three ways. First, ePPID cannot filter out all transient protein interactions, partly because of noise in the gene expression datasets we used. Second, Y2 H datasets may contain co-expressed protein pairs which are localized to different cellular compartments and seldom interact in nature. Third, ePPID may be underestimated based on incompleteness of $\mathrm{Y} 2 \mathrm{H}$ datasets [30,32], which is also reflected by the lowest average degree in the "Y2Hunion" dataset (column 5 of Additional file 1, Table S4).

\section{Global study of ePPID and other genomic variables for protein evolutionary rate}

A number of genomic variables, such as expression level $[16,25,50-52]$, functional dispensability $[25,53]$ and 
pleiotropic effect $[54,55]$, are proposed to be associated with protein evolutionary rate. Also, these variables may have redundancy since they are correlated with each other. Therefore, we next attempted to determine the possible confounding effect of these variables on the correlations between ePPID and protein evolutionary rate.

For this purpose, we collected two expression-related variables, mRNA abundance and protein abundance; two function-related variables, gene dispensability and gene pleiotropy, which were measured by the associated number of GO biological process terms of each gene; and two network-related variables, ePPID and betweenness (see Methods). We then carried out a principal component regression $[16,56]$ of protein evolutionary rate $\mathrm{dN}$ against the six predictor variables. The results for the "Y2H-union", "Combined-AP/MS" and "LC-multiple" datasets are summarized in Tables 4, 5 and 6, and those of the other three datasets are provided in Additional file 1, Table S6A-C.

Results show that the first principal component explains much more variance of protein evolutionary rate than the other components in all the six datasets. Thus, in the following, we focus on the first principal component to study the percentage contribution of ePPID. In the "Combined-AP/MS", "LC-multiple", "Updated-HC", "DIP-CORE" and "DIP-FULL" datasets, the contribution of ePPID to the first principal component is more than that of all other variables. In the "Y2H-union" dataset, the ePPID contribution is more than betweenness, but less than the other four variables. Consistently, the independent contribution of ePPID to the total variance of protein evolutionary rate $\mathrm{dN}$ explained by all the six principal components in most datasets is comparable to that of the expression-related variables of mRNA abundance and protein abundance (Additional file 1, Table S7). Similar results were obtained when using codon adaptation index (CAI) [36] instead of mRNA abundance or protein abundance to perform analysis (see Additional file 1, Text S6). Furthermore, when using three expression-related variables of mRNA abundance, protein abundance and CAI to perform analysis, ePPID still has a considerable and independent contribution to protein evolutionary rate (see Additional file 1, Text S6). We therefore concluded that ePPID has an important and independent effect on protein evolutionary rate, confirming the importance and novelty of our proposed new measure.

\section{Proteins with more co-expressed partners evolve more} slowly than those with less co-expressed partners

Since the evolutionary rate differences between different types of hub proteins have also been debated [18-23], we then wanted to study this problem by integrating co-
Table 4 Principal component regression analysis on six predictor variables and protein evolutionary rate for $\mathbf{7 5 2}$ yeast proteins in the "Y2H-union" dataset

\begin{tabular}{|c|c|c|c|c|c|c|c|}
\hline & \multicolumn{7}{|c|}{ Principal Components } \\
\hline & 1 & 2 & 3 & 4 & 5 & 6 & $\overline{\text { All }}$ \\
\hline $\begin{array}{l}\text { Percent variance } \\
\text { explained in } \mathrm{dN}\end{array}$ & $34.13^{* * *}$ & 0.55 & 0.46 & 0.38 & 0.23 & 0.00 & $35.74^{* * *}$ \\
\hline \multicolumn{8}{|l|}{$\begin{array}{l}\text { Percent } \\
\text { contributions }\end{array}$} \\
\hline mRNA abundance & 36.2 & 1.2 & 49.1 & 13.3 & 0.0 & 0.2 & \\
\hline protein abundance & 37.3 & 1.7 & 50.7 & 10.2 & 0.0 & 0.0 & \\
\hline gene dispensability & 10.4 & 2.0 & 0.0 & 37.2 & 49.9 & 0.4 & \\
\hline gene pleiotropy & 11.3 & 0.0 & 0.1 & 38.9 & 49.2 & 0.4 & \\
\hline ePPID & 3.9 & 45.4 & 0.0 & 0.3 & 0.4 & 49.9 & \\
\hline betweenness & 0.8 & 49.6 & 0.1 & 0.1 & 0.4 & 49.0 & \\
\hline
\end{tabular}

Note: ${ }^{*} \mathrm{P}<0.01$; ${ }^{*} \mathrm{P}<10^{-3}$; ${ }^{* *} \mathrm{P}<10^{-6}$; ${ }^{* * *} \mathrm{P}<10^{-9}$. Bold indicates that the predictor variable contributes at least $20 \%$ to the corresponding principal component.

expression data. We divided proteins into low, medium and high PPID bins and classified proteins into coexpressed and non-co-expressed proteins (see Methods). As a result, co-expressed proteins were found to have a significantly lower evolutionary rate than non-coexpressed proteins in each bin (Figure 3 and Additional file 1, Table S8A-C). At the same time, it should be noted that no significant difference in the high-PPID and medium-PPID bins was observed for the "Y2Hunion" dataset. However, the observed significantly lower evolutionary rate of co-expressed proteins in each bin may be confounded by PPID, but our further analysis did not support this notion (see Additional file 1, Text S7). These results further indicate that proteins with more permanent interaction partners are under higher evolutionary pressure and thus evolve more slowly.

ePPID helps the understanding of protein evolutionary rate in the Structural Interaction Network dataset

Protein interactions can also be studied from a structural perspective. We next applied our co-expressed and non-co-expressed protein classification method to hub proteins (with $\geq 5$ protein interaction partners) in the "SIN" dataset [22] and studied the relationship between ePPID and the number of binding interfaces. As shown in Additional file 1, Table S9, non-co-expressed hubs correspond mostly to singlish-interface hubs, whereas co-expressed hubs correspond mostly to multi-interface hubs (Fisher's exact test, $\mathrm{P}=1.63 \mathrm{e}-3$ ), suggesting that co-expression may be a characteristic of proteins with many distinct interfaces, which enable these proteins to interact together permanently. To test our hypothesis, we studied whether a correlation exists between ePPID and the number of binding interfaces from [22]. As it 
Table 5 Principal component regression analysis on six predictor variables and protein evolutionary rate for 723 yeast proteins in the "Combined-AP/MS" dataset

\begin{tabular}{lrrrrrrr}
\hline & \multicolumn{1}{l}{ Principal Components } & & & & \\
\cline { 2 - 7 } & $\mathbf{1}$ & $\mathbf{2}$ & $\mathbf{3}$ & $\mathbf{4}$ & $\mathbf{5}$ & $\mathbf{6}$ & All \\
\hline Percent variance explained in $\mathrm{dN}$ & $27.26^{* * *}$ & $7.77^{* * *}$ & $1.11^{*}$ & $0.92^{\#}$ & $0.83^{\#}$ & 0.01 & $37.90^{* * *}$ \\
\hline Percent contributions & & & & & & & \\
\hline mRNA abundance & $\mathbf{2 4 . 3}$ & 9.0 & 14.6 & $\mathbf{4 7 . 3}$ & 0.3 & 4.4 \\
\hline protein abundance & $\mathbf{2 2 . 8}$ & 15.9 & 13.4 & $\mathbf{4 1 . 3}$ & 0.1 & $\mathbf{6 . 5}$ \\
\hline gene dispensability & 8.7 & 2.5 & $\mathbf{2 0 . 8}$ & 1.0 & $\mathbf{6 3 . 2}$ & 3.8 \\
\hline gene pleiotropy & 0.0 & $\mathbf{3 7 . 2}$ & $\mathbf{4 0 . 1}$ & 0.0 & $\mathbf{2 0 . 6}$ & 2.1 \\
\hline ePPID & $\mathbf{2 4 . 5}$ & 16.6 & 4.3 & 7.5 & 0.0 & $\mathbf{4 7 . 0}$ \\
\hline betweenness & 19.7 & 18.9 & 6.8 & 2.8 & 15.8 & $\mathbf{3 6 . 1}$
\end{tabular}

Note: ${ }^{*} \mathrm{P}<0.01 ;{ }^{*} \mathrm{P}<10^{-3} ;{ }^{*} \mathrm{P}<10^{-6} ;{ }^{* * * \mathrm{P}}<10^{-9}$. Bold indicates that the predictor variable contributes at least $20 \%$ to the corresponding principal component.

turned out, the correlation is highly significant (Spearman rank correlation rho $=0.408, \mathrm{P}=4.40 \mathrm{e}-8)$. Considering the difficulties in obtaining protein structure data, this result suggests that the ePPID measure is a good predictor of the number of binding interfaces of a protein.

It is reported that protein evolutionary rate is actually more reflective of the number of distinct binding interfaces [22]. Yet we found that the correlation between the number of binding interfaces and protein evolutionary rate for hub proteins is not significant (Spearman rank correlation rho $=-0.211, \mathrm{P}=0.0561$ ) at the statistical significance level of 0.05 . On the other hand, the correlation between ePPID and protein evolutionary rate for hub proteins is highly significant (Spearman rank correlation rho $=-0.399, \mathrm{P}=1.89 \mathrm{e}-4)$. Similar results were obtained when statistical significance of the correlations is assessed by linear regression (Figure 4). Since ePPID explains the variance of protein evolutionary rate over three times higher than does the number of binding interfaces, we conclude that ePPID predicts protein evolutionary rate better than the number of binding interfaces. These results also implied that it is important to clearly distinguish permanent interfaces from transient interfaces when counting the number of a protein's distinct binding interfaces, because permanent and transient interfaces may contribute differently to protein evolutionary rate $[37,38]$.

It is also reported that multi-interface hubs have lower evolutionary rate than singlish-interface hubs (one-sided Wilcoxon rank sum test, $\mathrm{P}=8.66 \mathrm{e}-3$ ) [22]. Therefore, we next studied the effect of permanent and transient interfaces on protein evolutionary rate by integrating coexpression data. The hub proteins in the "SIN" dataset are grouped (see Methods) into four classes: non-coexpressed singlish-interface hubs, non-co-expressed multi-interface hubs, co-expressed singlish-interface hubs and co-expressed multi-interface hubs. The interfaces of co-expressed and non-co-expressed hubs are assumed to be permanent and transient, respectively. We found that non-co-expressed singlish-interface hubs, non-co-expressed multi-interface hubs and co-expressed singlish-interface hubs evolve at a similar rate. On the other hand, co-expressed multi-interface hubs evolve at a significantly lower rate (Figure 5), indicating that hubs with more permanent interfaces are subject to higher

Table 6 Principal component regression analysis on six predictor variables and protein evolutionary rate for 639 yeast proteins in the "LC-multiple" dataset

\begin{tabular}{lrrrrrrr}
\hline & \multicolumn{1}{l}{ Principal Components } & & & & \\
\cline { 2 - 6 } & $\mathbf{1}$ & $\mathbf{2}$ & $\mathbf{3}$ & $\mathbf{4}$ & $\mathbf{5}$ & $\mathbf{6}$ & All \\
\hline Percent variance explained in $\mathrm{dN}$ & $27.43^{* * *}$ & $6.90^{* * *}$ & $1.40^{*}$ & $0.94^{\#}$ & 0.32 & 0.26 & $37.24^{* * *}$ \\
\hline Percent contributions & & & & & & \\
\hline mRNA abundance & $\mathbf{2 1 . 4}$ & $\mathbf{2 2 . 0}$ & $\mathbf{5 0 . 1}$ & 6.0 & 0.0 & 0.5 \\
\hline protein abundance & $\mathbf{2 0 . 7}$ & $\mathbf{2 1 . 7}$ & $\mathbf{4 4 . 3}$ & 6.3 & 1.6 & 5.3 \\
\hline gene dispensability & 13.0 & 0.0 & 0.4 & $\mathbf{6 5 . 6}$ & 19.9 & 1.1 \\
\hline gene pleiotropy & 2.8 & $\mathbf{2 5 . 6}$ & 0.8 & $\mathbf{2 2 . 0}$ & $\mathbf{4 8 . 6}$ & 0.2 \\
\hline ePPID & $\mathbf{2 5 . 9}$ & 10.4 & 3.6 & 0.1 & 6.8 & $\mathbf{5 3 . 2}$ \\
\hline betweenness & 16.3 & $\mathbf{2 0 . 3}$ & 0.7 & 0.0 & $\mathbf{2 3 . 0}$ & $\mathbf{3 9 . 7}$
\end{tabular}

Note: ${ }^{\#} \mathrm{P}<0.01 ;{ }^{*} \mathrm{P}<10^{-3} ;{ }^{* *} \mathrm{P}<10^{-6} ;{ }^{* * *} \mathrm{P}<10^{-9}$. Bold indicates that the predictor variable contributes at least $20 \%$ to the corresponding principal component. 


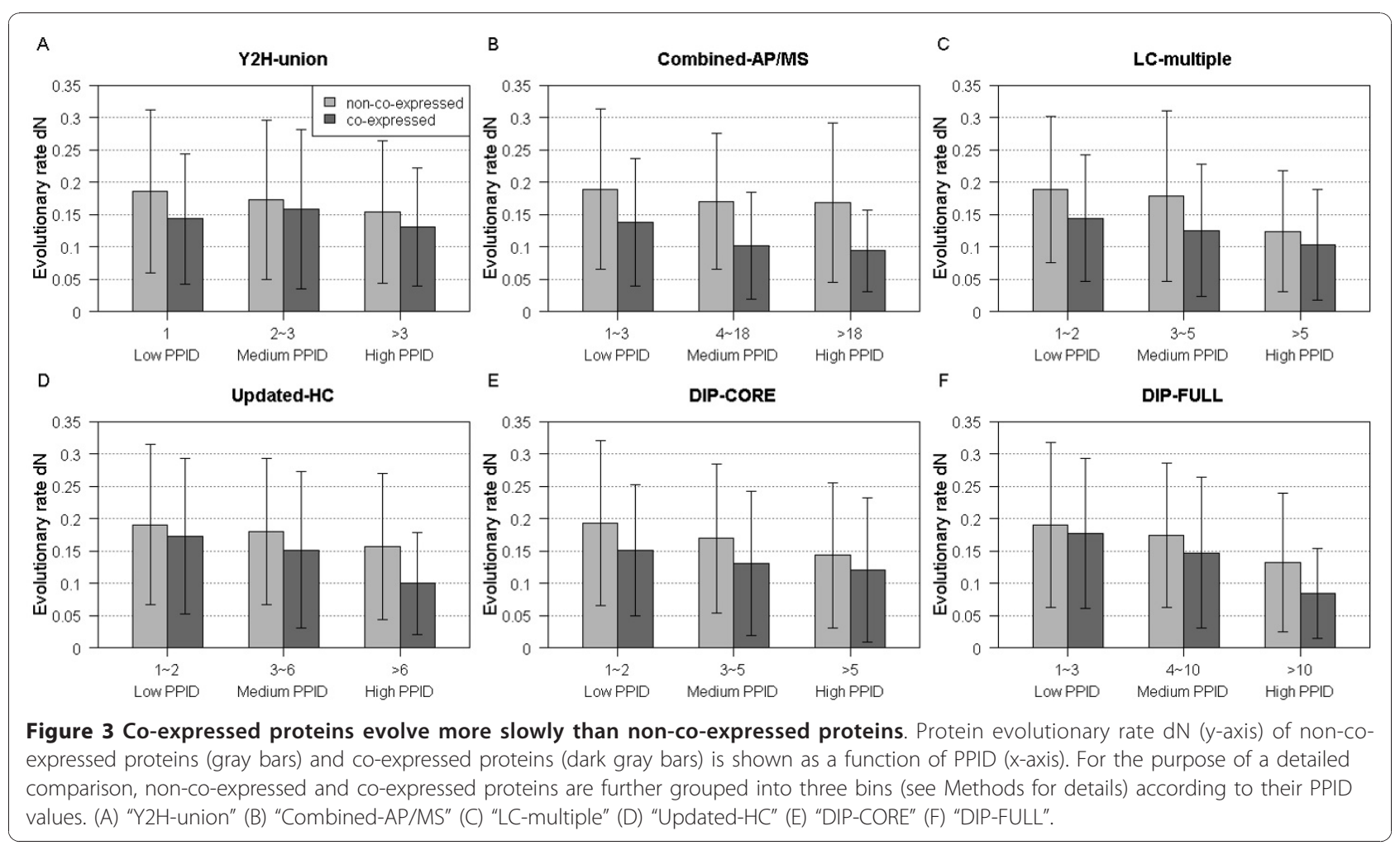

evolutionary constraints and thus evolve more slowly. This result is in clear contrast with the finding of [23] where the evolutionary rate difference between multiiMotif hubs and singlish-iMotif hubs is not found to be significant. Thus, we conclude that the difference in evolutionary rate between singlish-interface (singlishiMotif) hubs and multi-interface (multi-iMotif) hubs is better clarified by the ePPID measure. In fact, more significant results were obtained when using the "UpdatedSIN" dataset, which has a relatively larger size than the "SIN" dataset (see Additional file 1, Text S8). Finally, we note that all the above results can be replicated if we define protein evolutionary rate as $\mathrm{dN} / \mathrm{dS}$ or $\mathrm{dN} / \mathrm{dS}$ ' (ratio of non-synonymous substitutions to adjusted synonymous substitutions; data not shown).

\section{Application of ePPID in human data}

To see whether our result for yeast can be obtained in other species, we obtained the relevant data for human and computed ePPID for each protein (see Additional file 1, Text $\mathrm{S} 9$ for details). As a result, we found that the percent variance of evolutionary rate explained by ePPID is higher than that explained by PPID (Figure 6). The Spearman rank correlation between PPID and protein evolutionary rate is -0.172 and its P-value is $1.24 \mathrm{e}$ 58 , while the Spearman rank correlation between ePPID and protein evolutionary rate is -0.206 and its $\mathrm{P}$-value is 2.71e-83. Thus, we concluded that our result also holds in human and will study if it can be obtained in more species in the future.

\section{Discussion}

DNA mutations, especially those in protein-coding regions, are a driving force of biological novelties. Understanding protein evolutionary rate is thus an important topic. Along with rapid progress in highthroughput methods in recent years, it is possible to study protein evolutionary rate from many perspectives. Protein interactions, which are believed to exert an important selective pressure on protein evolution at the functional level, have been heavily studied in recent years. However, owing to the complexity in experimental setup and the biological system itself, controversial results have led investigators to debate the association between protein-protein interaction degree (PPID) and protein evolutionary rate.

Proteins with higher PPID are assumed to have a greater proportion of residues involved in interactions and thus evolve more slowly than proteins with lower PPID [6,9]. This assumption was supported by the fact that ePPID, which measures the number of a protein's permanent interaction partners, could better predict protein evolutionary rate. In $\mathrm{Y} 2 \mathrm{H}$ datasets which are enriched for transient physical interactions, ePPID mainly filters out a protein's transient physical interactions and thus reflects the number of the protein's 


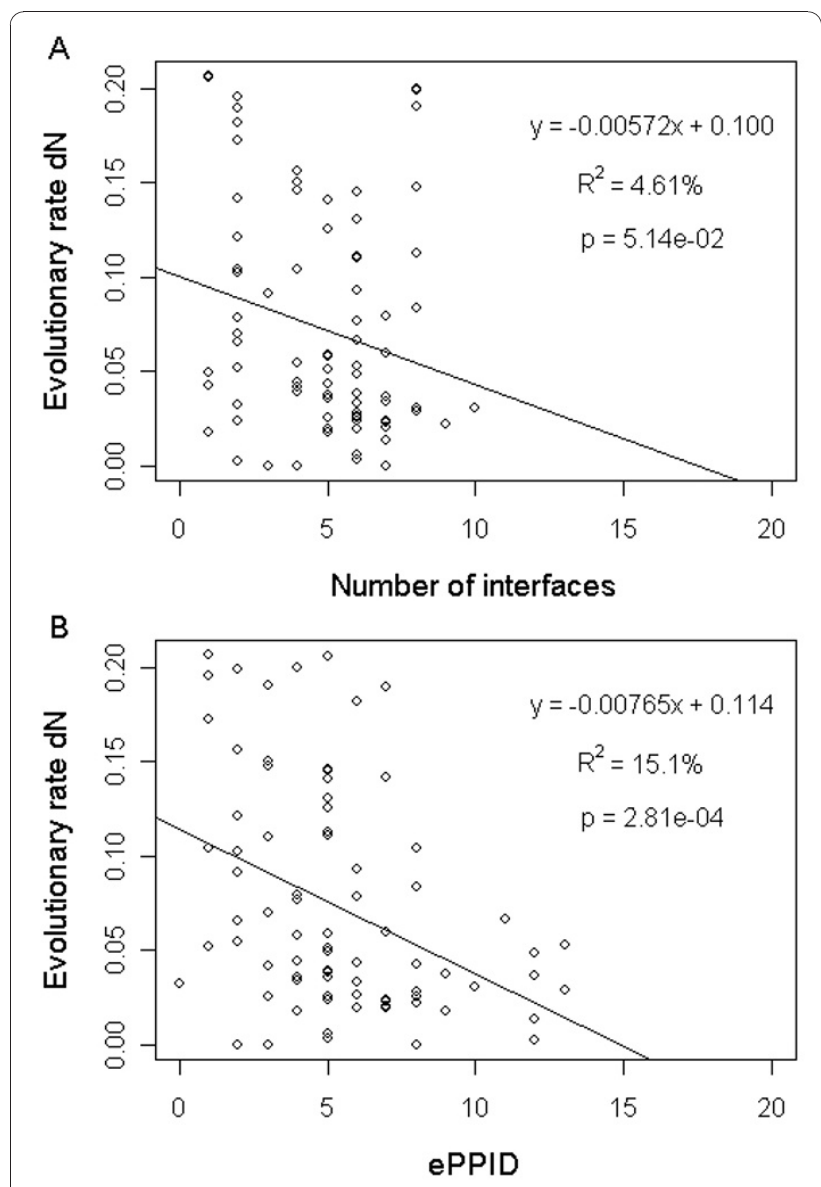

Figure 4 Relationship of protein evolutionary rate with the number of interfaces and ePPID. Scatter plots of protein

evolutionary rate $d N$ versus (A) the number of interfaces and (B) ePPID together with the linear regression fit in the "SIN" dataset.

permanent physical interactions. Though the filtered interactions of a protein contribute to the PPID of the protein, they may not contribute to the proportion of the protein's residues involved in interactions (i.e., the protein tends to interact with its different filtered partners through the same binding interface). As demonstrated by our results, transient physical interactions on average indeed exert lower selective constraints on protein evolution. On the other hand, in AP/MS-related datasets, the protein pairs may not physically interact in nature; rather, they appear in the same protein complexes. In such datasets, ePPID mainly filters out a protein's transient co-complex associations and thus reflects the number of the protein's permanent co-complex associations. Though the filtered interactions of a protein may contribute to the proportion of the protein's residues involved in interactions (i.e., the protein may interact with its filtered partners through multiple distinct transient interfaces), they do not contribute to the proportion of the protein's residues involved in

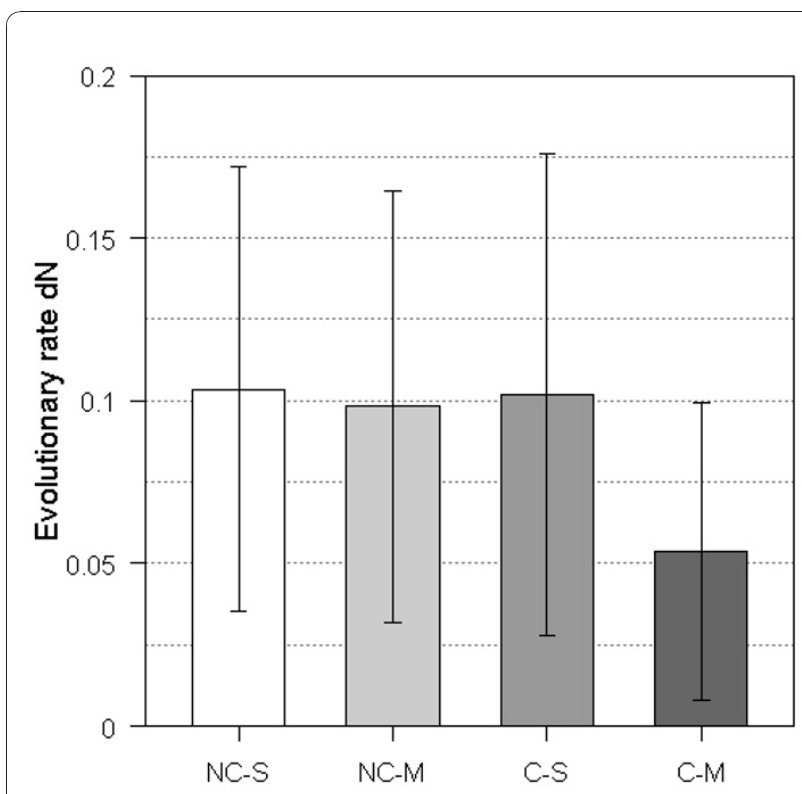

Figure 5 Effects of permanent and transient interfaces on protein evolutionary rate. Mean and standard deviation of protein evolutionary rate $\mathrm{dN}$ in the "SIN" dataset are shown for non-coexpressed proteins with single interface (NC-S, in a total of 10 proteins), non-co-expressed proteins with multiple interfaces (NC-M, in a total of 12 proteins), co-expressed proteins with single interface (C-S, in a total of 10 proteins) and co-expressed proteins with multiple interfaces (C-M, in a total of 51 proteins). C-M evolve significantly more slowly than NC-S ( $P=1.05 \mathrm{e}-02)$, NC-M ( $P=1.34 \mathrm{e}-$ $02)$ and $C-S(P=2.29 e-02)$. Other comparisons did not yield significant results (i.e., $P>0.05$ ). $P$ is calculated by one-sided Wilcoxon rank sum test.

permanent interactions. Thus, they should also be filtered out because they may not exert higher selective constraints on protein evolution, which is also demonstrated by our results. However, $\mathrm{Y} 2 \mathrm{H}$ datasets are more likely to contain false negatives (incompleteness of $\mathrm{Y} 2 \mathrm{H}$ datasets) and ePPID in such datasets may be underestimated, whereas AP/MS-related datasets are more likely to contain false positives (indirect non-physical interactions) and ePPID in such datasets may be overestimated. We hope to study this effect when more reliable and complete protein interaction data become available in the future. Despite this slight difference, our results demonstrated a clearer role of protein interaction degree as a constraint on protein evolution.

\section{Conclusions}

In this work, we performed extensive studies to identify how protein interactions, as measured by PPID, affect protein evolutionary rate. By carefully comparing experimental setups, we observed that $\mathrm{Y} 2 \mathrm{H}$ assays may have introduced a considerable amount of transient protein interactions. On this basis, we hypothesized 


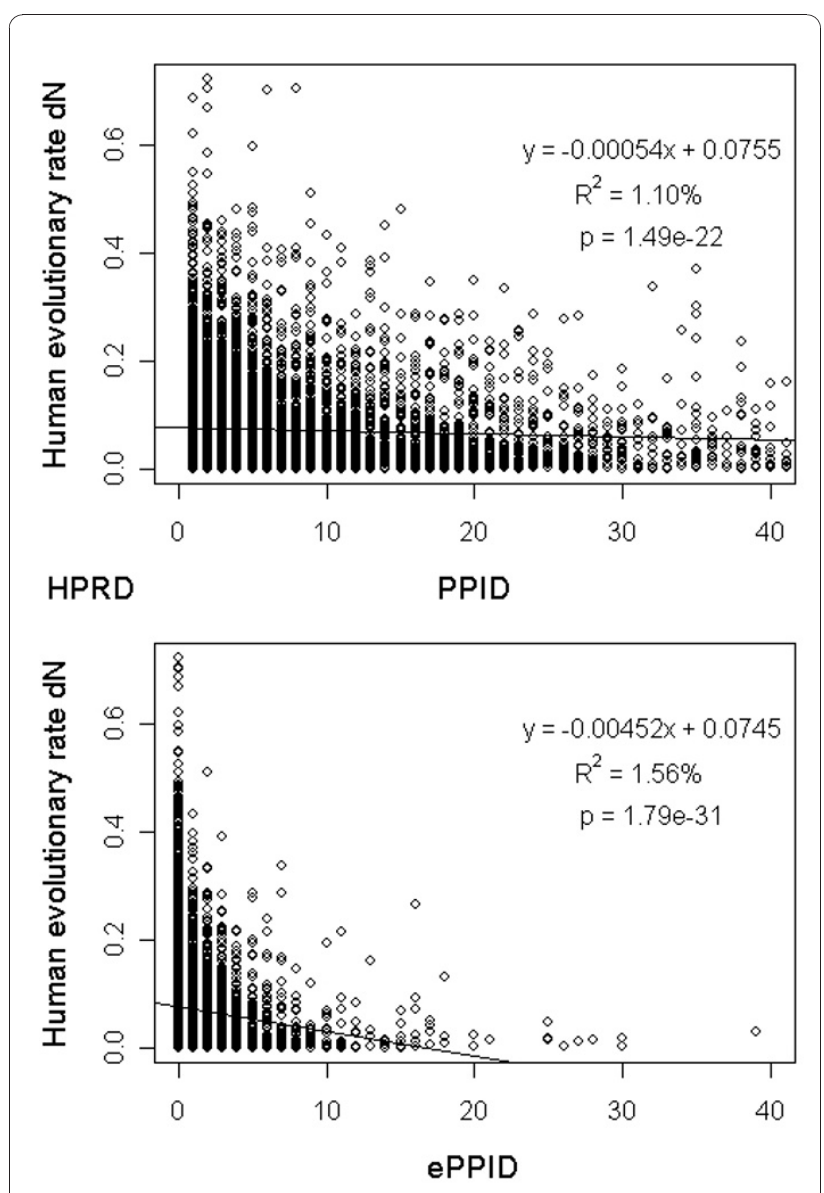

Figure 6 Relationship of human protein evolutionary rate dN with PPID and ePPID. Scatter plots of human protein evolutionary rate $\mathrm{dN}$ versus PPID (upper panel) and ePPID (bottom panel) together with the linear regression fit in the "HPRD" dataset.

that the difference in experimental methods contributes to our inability to clearly define how PPID affects protein evolutionary rate. This hypothesis was confirmed by introducing a new protein interaction degree measure, the co-expressed protein-protein interaction degree (ePPID). Since ePPID is a measure that integrates protein interactions with gene coexpression information, it can filter out many transient protein interactions. As a result, ePPID gives a better prediction of protein evolutionary rate than PPID in the various protein interaction datasets tested. The relationship between ePPID and protein evolutionary rate is also robustly significant in all protein interaction datasets, which was not possible when using PPID in previous studies. We also investigated the redundancy between several variables that may affect protein evolutionary rate against the contribution of ePPID and found that ePPID makes an independent contribution to protein evolutionary rate. This result suggests the novelty of ePPID as an important determinant of protein evolutionary rate. Moreover, the application on hub proteins in the Structural Interaction Network provides further support that ePPID also gives a better prediction of protein evolutionary rate than the number of distinct binding interfaces and clarified the slower evolution of co-expressed multi-interface hub proteins over that of other hub proteins.

In summary, our work provides a new protein interaction degree measure by integrating protein interaction datasets with gene expression datasets. This new measure has, at least in part, resolved the longstanding debates on the role of protein interactions in affecting protein evolutionary rate. Finally, we have found that this result also holds in human. We will study if this can be observed in more species in the future.

\section{Methods}

Protein interaction datasets

To study the effect of experimental bias, reliability and completeness, we collected nine different yeast protein interaction datasets. We used the "Y2H-union", "Combined-AP/MS" and "LC-multiple" datasets to represent typical protein interaction datasets obtained from $\mathrm{Y} 2 \mathrm{H}$ assays, the AP/MS method and literature curation, respectively. To account for data quality (confidence), we also used the filtered yeast interactome ("FYI"), the Structural Interaction Network ("SIN"), "DIP-CORE" and the updated high-confidence dataset ("Updated-HC") as highconfidence datasets. In addition, the "SIN" dataset was also used to study the evolutionary rate of hub proteins through a mechanistic perspective. In contrast, we used the "DIP-FULL" and "Eight-union" datasets to account for completeness. The nine datasets are listed below.

1) $\mathrm{Y} 2 \mathrm{H}$-union: the union of three high-throughput $\mathrm{Y} 2$ $\mathrm{H}$ datasets: Uetz-screen [57], Ito-core [58] and CCSBYI1 [32].

2) Combined-AP/MS: an integrated dataset [59] of two high-throughput AP/MS datasets [60,61].

3) LC-multiple: a protein interaction dataset based on the literature. Each protein interaction must have been curated from $\geq 2$ different publications [62].

4) FYI: the filtered yeast interactome obtained from [24].

5) SIN: the Structural Interaction Network dataset obtained from [22].

6) Updated-HC: the updated high-confidence dataset obtained from [21].

7) DIP-CORE: the core dataset derived from the database of interacting proteins (DIP) [42,43].

8) DIP-FULL: the full dataset derived from the database of interacting proteins (DIP) [43].

9) Eight-union: the union of the above eight datasets.

The network properties of the nine datasets are summarized in Additional file 1, Table S4. The overlap of 
interactions between the nine datasets was shown in Additional file 1, Table S5A-C. We analyzed the six protein interaction datasets 1), 2), 3), 6), 7) and 8) in the main text and the analysis results of the other three 4), 5) and 9) were provided in Additional file 1, Text S1.

\section{Data sources for correlation and principal component regression analyses}

Evolutionary rate data (non-synonymous substitutions per site $\mathrm{dN}$ ), which is based on the four-way yeast species alignments for 3,036 Saccharomyces cerevisiae genes, were obtained from [25]. Specifically, orthologous genes were aligned by using ClustalW [63] and $\mathrm{dN}$ was then estimated using PAML [64]. Three other protein evolutionary rate data (corresponding to different out-group controls, including S.cer vs S.par, S.cer vs S.mik and S.cer vs S.bay) were obtained from [49]. mRNA abundance data were obtained from [35]. Protein abundance data were obtained from [33]. Codon adaptation index (CAI), which measures synonymous codon usage bias [65], was obtained from [36]. Gene dispensability, measured by the average growth rates of homozygous deletion strains, was obtained from [66]. The associated number of GO biological process terms of a gene [67], used as a measure of gene pleiotropy, was obtained from the Saccharomyces Genome Database [68]. Protein betweenness, measured by the total number of shortest paths going through a protein in a protein interaction network $[46,47]$, was calculated by using R [69] with the package "igraph" [70].

Partial correlation analysis is frequently used to determine the confounding effect of variables such as protein abundance on the relationship between PPID and protein evolutionary rate $[6,9,13-15,25,51,71]$. It is also reported that principal component regression analysis can provide a complementary analysis to partial correlation analysis [72] and that the relative contributions of the transformed predictors to the overall regression model can be evaluated independently and reliably [16]. In this paper, we performed both principal component regression and partial correlation analyses to understand protein evolutionary rate. Principal component regression was performed by using R with the package "pls" [73]. Before carrying out the principal component analysis, all variables were log transformed, except dispensability, and all predictor variables were standardized to zero mean and unit variance. It should be noted that a small constant of 0.001 was added to protein evolutionary rate $\mathrm{dN}$ as described in [25] to avoid zero values. A small constant of 0.1 was added to ePPID and betweenness to avoid zero values and we demonstrated that our results were not sensitive to these constants (see Additional file 1, Text S10). The statistical significance levels were determined according to Drummond et al. [16]. Partial correlation analysis was performed by using $\mathrm{R}$ with the function provided by Kim and Yi [72]. The method for computing the percentage variance of protein evolutionary rate explained by ePPID when protein abundance is controlled for was as follows. First, we performed a linear regression of protein evolutionary rate $\mathrm{dN}$ against $\log$ (protein abundance) and obtained $\mathrm{dN}=\mathrm{f}$ (Log(protein abundance)). We then computed the residue, i.e., $d N \_r e s i d u e ~=d N-f(\log ($ protein abundance $))$. Finally, we performed a linear regression of the residue against ePPID: dN_residue = g(ePPID $)$, and obtained the explained variance.

\section{Gene expression datasets}

We collected ten gene expression datasets [74-83], each with more than 50 samples (conditions), from the Yeast Functional Genomics Database [84] and the Saccharomyces Genome Database [68]. Genes with missing value in $>30 \%$ of the samples in a dataset were removed. Remaining missing values were imputed by the KNN impute algorithm with $\mathrm{K}=10$ using Euclidean distance [85], and technical replicates (i.e., spot repeats and dye swaps) were averaged.

\section{Construction of gene co-expression networks}

Pearson correlation coefficient (PCC) $r$ is used as a similarity measure between the expression profiles of two genes. The PCC $r$ was then converted into $z$-score using Fisher transformation:

$$
z(r)=\frac{\sqrt{n-3}}{2} \log \frac{1+r}{1-r}
$$

which approximately follows a standard normal distribution under the hypothesis of independence, where $n$ is the sample size. We only considered positive correlations since they are reported to be more reflective of functional similarity than negative correlations [86]. Next, P-values were obtained for the null hypothesis of no positive correlations and were corrected for multiple hypothesis testing by using false discovery rate (FDR) control procedure [87], and the adjusted P-values were set at the threshold of 0.001 per dataset $($ FDR $=0.001)$. In addition, we only considered those pairs that are among the top 10 percent of all possible correlations $(\mathrm{PER}=10 \%)$ to avoid introducing too many high correlations. Our two-stage threshold selection procedure is similar to the procedure that controls both statistical significance and biological significance in $[86,88]$ and we demonstrated that our results were not sensitive to different thresholds of FDR and PER (see Additional file 1, Text S11). For each gene expression dataset, two genes are declared to be co-expressed if their correlation coefficient is above the thresholds of both FDR and PER. 


\section{Definition of co-expressed protein-protein interaction degree (ePPID) and classification of proteins}

In a given protein interaction dataset, let $\mathrm{PPI}_{\mathrm{g}}$ denote the set of interaction partners of a given protein g. By filtering out the potential transient interaction partners in $\mathrm{PPI}_{\mathrm{g}}$, we want to integrate gene co-expression in a way that allows us to identify the partners with which protein $g$ can permanently interact. To explain, we can calculate the $\mathrm{z}$-scores of co-expression between protein $\mathrm{g}$ and all genes in $\mathrm{PPI}_{\mathrm{g}}$ for each gene expression dataset. Let $\mathrm{ePPI}_{\mathrm{g}}(\mathrm{i})$ denote the number of genes that are found to be significantly co-expressed with gene $\mathrm{g}$ in gene expression dataset $i$ ( $i=1,2, \ldots, 10$; see previous paragraph). The co-expressed protein-protein interaction degree (ePPID) of protein $\mathrm{g}$ is then defined as ePPID $\mathrm{g}=$ $\max \left(\mathrm{ePPI}_{\mathrm{g}}(\mathrm{i}) ; \mathrm{i}=1,2, \ldots, 10\right)$. In addition, we tried other co-expressed protein-protein interaction degree measures to demonstrate the robustness of our results (see Additional file 1, Text S4).

To study whether evolutionary rate differences between different types of proteins can be better clarified by distinguishing permanent interactions from transient interactions, we divided proteins into low, medium and high PPID bins, with the high-PPID bin containing about $20 \%$ of the total number of proteins (also called hubs) in each protein interaction dataset. Similar to the concept behind the date and party hub definition in [24], we further grouped proteins into two classes. A protein was defined as co-expressed if the ratio of ePPID to PPID (ePPID/PPID) is $\geq 0.5$; otherwise, it was defined as a non-co-expressed protein.

To study the contribution of permanent and transient interfaces to protein evolutionary rate in the "SIN" dataset, the ePPID of hub proteins in the "SIN" dataset was calculated similarly, and the hub proteins were further grouped into four classes: non-co-expressed singlishinterface hubs, non-co-expressed multi-interface hubs, co-expressed singlish-interface hubs and co-expressed multi-interface hubs by taking intersections.

\section{Additional material}

Additional file 1: Supplementary texts, figures and tables. This file contains Supplementary Texts S1-S11, Figures S1-S4 and Tables S1-S38.

\footnotetext{
Abbreviations

APCC: average Pearson correlation coefficient; AP/MS: affinity purifications followed by mass spectrometry; CAl: codon adaptation index; $\mathrm{dN}$ : nonsynonymous substitution rate; ePPID: co-expressed protein-protein interaction degree; FDR: false discovery rate; GO: Gene Ontology; PCC: Pearson correlation coefficient; PER: percent of all possible correlations; PPID: protein-protein interaction degree; $\mathrm{Y} 2 \mathrm{H}$ : yeast two-hybrid.
}

\section{Acknowledgements}

XM is supported by NIH grant HG001696 to Michael Q Zhang. The authors greatly appreciate the comments from the three anonymous reviewers, which have significantly improved this manuscript. We thank Yangbo He for suggestions on calculating the percent variance when controlling for confounding variable.

\section{Author details}

${ }^{1}$ Department of Computer Science and Engineering, Shanghai Jiao Tong University, Shanghai, 200240, China. ${ }^{2}$ Program in Computational Biology and Bioinformatics, Yale University, New Haven, CT 06520, USA. ${ }^{3}$ Department of Molecular and Cell Biology, Center for Systems Biology, University of Texas at Dallas, Richardson, TX 75080, USA.

\section{Authors' contributions}

$\mathrm{KP}$ and $\mathrm{XM}$ conceived and designed the experiment; HS and XM supervised the experiment; KP, CC, ZX, HS and XM conducted the experiment and wrote the manuscript. All authors have read and approved the final manuscript.

Received: 26 February 2010 Accepted: 30 December 2010 Published: 30 December 2010

\section{References}

1. Xia Y, Franzosa EA, Gerstein MB: Integrated assessment of genomic correlates of protein evolutionary rate. PLoS Comput Biol 2009, 5: e1000413.

2. Park D, Choi SS: Why proteins evolve at different rates: the functional hypothesis versus the mistranslation-induced protein misfolding hypothesis. FEBS Lett 2009, 583:1053-1059.

3. Rocha EP: The quest for the universals of protein evolution. Trends Genet 2006, 22:412-416.

4. Pal C, Papp B, Lercher MJ: An integrated view of protein evolution. Nat Rev Genet 2006, 7:337-348.

5. Mclnerney JO: The causes of protein evolutionary rate variation. Trends Ecol Evol 2006, 21:230-232.

6. Fraser $\mathrm{HB}$, Hirsh AE, Steinmetz LM, Scharfe C, Feldman MW: Evolutionary rate in the protein interaction network. Science 2002, 296:750-752.

7. Zuckerkandl E: Evolutionary processes and evolutionary noise at the molecular level. I. Functional density in proteins. J Mol Evol 1976, 7:167-183.

8. Jordan IK, Wolf YI, Koonin EV: No simple dependence between protein evolution rate and the number of protein-protein interactions: only the most prolific interactors tend to evolve slowly. BMC Evol Biol 2003, 3:1

9. Fraser $H B$, Wall DP, Hirsh AE: A simple dependence between protein evolution rate and the number of protein-protein interactions. BMC Evol Biol 2003, 3:11.

10. Hahn MW, Conant GC, Wagner A: Molecular evolution in large genetic networks: does connectivity equal constraint? J Mol Evol 2004, 58:203-211.

11. Saeed R, Deane CM: Protein protein interactions, evolutionary rate, abundance and age. BMC Bioinformatics 2006, 7:128.

12. Batada NN, Hurst LD, Tyers M: Evolutionary and physiological importance of hub proteins. PLoS Comput Biol 2006, 2:e88.

13. Bloom JD, Adami C: Apparent dependence of protein evolutionary rate on number of interactions is linked to biases in protein-protein interactions data sets. BMC Evol Biol 2003, 3:21.

14. Fraser HB, Hirsh AE: Evolutionary rate depends on number of proteinprotein interactions independently of gene expression level. BMC Evol Biol 2004, 4:13.

15. Bloom JD, Adami C: Evolutionary rate depends on number of proteinprotein interactions independently of gene expression level: response. BMC Evol Biol 2004, 4:14.

16. Drummond DA, Raval A, Wilke CO: A single determinant dominates the rate of yeast protein evolution. Mol Biol Evol 2006, 23:327-337.

17. Plotkin JB, Fraser HB: Assessing the determinants of evolutionary rates in the presence of noise. Mol Biol Evol 2007, 24:1113-1121.

18. Fraser HB: Modularity and evolutionary constraint on proteins. Nat Genet 2005, 37:351-352. 
19. Batada NN, Reguly T, Breitkreutz A, Boucher L, Breitkreutz BJ, Hurst LD Tyers M: Stratus not altocumulus: a new view of the yeast protein interaction network. PLOS Biol 2006, 4:e317.

20. Bertin N, Simonis N, Dupuy D, Cusick ME, Han JD, Fraser HB, Roth FP, Vidal M: Confirmation of organized modularity in the yeast interactome. PLOS Biol 2007, 5:e153.

21. Batada NN, Reguly T, Breitkreutz A, Boucher L, Breitkreutz BJ, Hurst LD, Tyers M: Still stratus not altocumulus: further evidence against the date/ party hub distinction. PLOS Biol 2007, 5:e154.

22. Kim PM, Lu LJ, Xia Y, Gerstein MB: Relating three-dimensional structures to protein networks provides evolutionary insights. Science 2006, 314:1938-1941.

23. Aragues R, Sali A, Bonet J, Marti-Renom MA, Oliva B: Characterization of protein hubs by inferring interacting motifs from protein interactions. PLoS Comput Biol 2007, 3:1761-1771.

24. Han JD, Bertin N, Hao T, Goldberg DS, Berriz GF, Zhang LV, Dupuy D, Walhout AJ, Cusick ME, Roth FP, Vidal M: Evidence for dynamically organized modularity in the yeast protein-protein interaction network. Nature 2004, 430:88-93.

25. Wall DP, Hirsh AE, Fraser HB, Kumm J, Giaever G, Eisen MB, Feldman MW: Functional genomic analysis of the rates of protein evolution. Proc Nat/ Acad Sci USA 2005, 102:5483-5488.

26. von Mering C, Krause R, Snel B, Cornell M, Oliver SG, Fields S, Bork P: Comparative assessment of large-scale data sets of protein-protein interactions. Nature 2002, 417:399-403.

27. Jansen $R, Y u$ H, Greenbaum D, Kluger Y, Krogan NJ, Chung S, Emili A, Snyder M, Greenblatt JF, Gerstein M: A Bayesian networks approach for predicting protein-protein interactions from genomic data. Science 2003, 302:449-453.

28. Sprinzak E, Sattath S, Margalit H: How reliable are experimental proteinprotein interaction data? J Mol Biol 2003, 327:919-923.

29. Bader JS, Chaudhuri A, Rothberg JM, Chant J: Gaining confidence in highthroughput protein interaction networks. Nat Biotechnol 2004, 22:78-85.

30. Hart GT, Ramani AK, Marcotte EM: How complete are current yeast and human protein-interaction networks? Genome Biol 2006, 7:120

31. Shoemaker BA, Panchenko AR: Deciphering protein-protein interactions. Part I. Experimental techniques and databases. PLoS Comput Biol 2007, 3:e42.

32. Yu H, Braun P, Yildirim MA, Lemmens I, Venkatesan K, Sahalie J, HirozaneKishikawa T, Gebreab F, Li N, Simonis N, et al: High-quality binary protein interaction map of the yeast interactome network. Science 2008, 322:104-110.

33. Ghaemmaghami S, Huh WK, Bower K, Howson RW, Belle A, Dephoure N, O'Shea EK, Weissman JS: Global analysis of protein expression in yeast. Nature 2003, 425:737-741.

34. Newman JR, Ghaemmaghami S, Ihmels J, Breslow DK, Noble M, DeRisi JL, Weissman JS: Single-cell proteomic analysis of S. cerevisiae reveals the architecture of biological noise. Nature 2006, 441:840-846.

35. Holstege FC, Jennings EG, Wyrick JJ, Lee TI, Hengartner CJ, Green MR, Golub TR, Lander ES, Young RA: Dissecting the regulatory circuitry of a eukaryotic genome. Cell 1998, 95:717-728.

36. Coghlan A, Wolfe KH: Relationship of codon bias to mRNA concentration and protein length in Saccharomyces cerevisiae. Yeast 2000, 16:1131-1145.

37. Mintseris J, Weng Z: Structure, function, and evolution of transient and obligate protein-protein interactions. Proc Natl Acad Sci USA 2005, 102:10930-10935.

38. Choi YS, Yang JS, Choi Y, Ryu SH, Kim S: Evolutionary conservation in multiple faces of protein interaction. Proteins 2009, 77:14-25.

39. Teichmann SA: The constraints protein-protein interactions place on sequence divergence. J Mol Biol 2002, 324:399-407.

40. Jansen R, Greenbaum D, Gerstein M: Relating whole-genome expression data with protein-protein interactions. Genome Res 2002, 12:37-46.

41. Ekman D, Light S, Bjorklund AK, Elofsson A: What properties characterize the hub proteins of the protein-protein interaction network of Saccharomyces cerevisiae? Genome Biol 2006, 7:R45.

42. Deane CM, Salwinski L, Xenarios I, Eisenberg D: Protein interactions: two methods for assessment of the reliability of high throughput observations. Mol Cell Proteomics 2002, 1:349-356.

43. Salwinski L, Miller CS, Smith AJ, Pettit FK, Bowie JU, Eisenberg D: The Database of Interacting Proteins: 2004 update. Nucleic Acids Res 2004, 32: D449-451.
44. Agarwal S, Deane CM, Porter MA, Jones NS: Revisiting date and party hubs: novel approaches to role assignment in protein interaction networks. PLoS Comput Biol 2010, 6:e1000817.

45. Brown KR, Jurisica I: Online predicted human interaction database. Bioinformatics 2005, 21:2076-2082.

46. Freeman LC: A set of measures of centrality based on betweenness. Sociometry 1977, 40:35-41.

47. Girvan M, Newman ME: Community structure in social and biological networks. Proc Natl Acad Sci USA 2002, 99:7821-7826.

48. Hahn MW, Kern AD: Comparative genomics of centrality and essentiality in three eukaryotic protein-interaction networks. Mol Biol Evol 2005, 22:803-806.

49. Kellis M, Patterson N, Endrizzi M, Birren B, Lander ES: Sequencing and comparison of yeast species to identify genes and regulatory elements. Nature 2003, 423:241-254.

50. Pal C, Papp B, Hurst LD: Highly expressed genes in yeast evolve slowly. Genetics 2001, 158:927-931.

51. Rocha EP, Danchin A: An analysis of determinants of amino acids substitution rates in bacterial proteins. Mol Biol Evol 2004, 21:108-116.

52. Drummond DA, Bloom JD, Adami C, Wilke CO, Arnold FH: Why highly expressed proteins evolve slowly. Proc Natl Acad Sci USA 2005, 102:14338-14343.

53. Hirsh $A E$, Fraser $H B$ : Protein dispensability and rate of evolution. Nature 2001, 411:1046-1049.

54. Otto SP: Two steps forward, one step back: the pleiotropic effects of favoured alleles. Proc Biol Sci 2004, 271:705-714

55. Salathe $M$, Ackermann $M$, Bonhoeffer $S$ : The effect of multifunctionality on the rate of evolution in yeast. Mol Biol Evol 2006, 23:721-722.

56. Mandel J: Use of the singular value decomposition in regression analysis. Am Stat 1982, 36:15-24

57. Uetz P, Giot L, Cagney G, Mansfield TA, Judson RS, Knight JR, Lockshon D, Narayan $V$, Srinivasan $M$, Pochart $P$, et al: A comprehensive analysis of protein-protein interactions in Saccharomyces cerevisiae. Nature 2000, 403:623-627.

58. Ito T, Chiba T, Ozawa R, Yoshida M, Hattori M, Sakaki Y: A comprehensive two-hybrid analysis to explore the yeast protein interactome. Proc Natl Acad Sci USA 2001, 98:4569-4574.

59. Collins SR, Kemmeren P, Zhao XC, Greenblatt JF, Spencer F, Holstege FC, Weissman JS, Krogan NJ: Toward a comprehensive atlas of the physical interactome of Saccharomyces cerevisiae. Mol Cell Proteomics 2007, 6:439-450

60. Gavin AC, Aloy P, Grandi P, Krause R, Boesche M, Marzioch M, Rau C, Jensen $L$, Bastuck S, Dumpelfeld B, et al: Proteome survey reveals modularity of the yeast cell machinery. Nature 2006, 440:631-636.

61. Krogan NJ, Cagney G, Yu H, Zhong G, Guo X, lgnatchenko A, Li J, Pu S, Datta N, Tikuisis AP, et al: Global landscape of protein complexes in the yeast Saccharomyces cerevisiae. Nature 2006, 440:637-643.

62. Reguly T, Breitkreutz A, Boucher L, Breitkreutz BJ, Hon GC, Myers CL, Parsons A, Friesen $\mathrm{H}$, Oughtred $\mathrm{R}$, Tong $\mathrm{A}$, et al: Comprehensive curation and analysis of global interaction networks in Saccharomyces cerevisiae. J Biol 2006, 5:11

63. Thompson JD, Higgins DG, Gibson TJ: CLUSTAL W: improving the sensitivity of progressive multiple sequence alignment through sequence weighting, position-specific gap penalties and weight matrix choice. Nucleic Acids Res 1994, 22:4673-4680.

64. Yang Z: Phylogenetic analysis by maximum likelihood London: University College; 2002

65. Sharp PM, Li WH: The codon Adaptation Index-a measure of directional synonymous codon usage bias, and its potential applications. Nucleic Acids Res 1987, 15:1281-1295.

66. Deutschbauer AM, Jaramillo DF, Proctor M, Kumm J, Hillenmeyer ME, Davis RW, Nislow C, Giaever G: Mechanisms of haploinsufficiency revealed by genome-wide profiling in yeast. Genetics 2005, 169:1915-1925.

67. Ashburner M, Ball CA, Blake JA, Botstein D, Butler H, Cherry JM, Davis AP, Dolinski K, Dwight SS, Eppig JT, et al: Gene ontology: tool for the unification of biology. The Gene Ontology Consortium. Nat Genet 2000, 25:25-29.

68. Cherry JM, Adler C, Ball C, Chervitz SA, Dwight SS, Hester ET, Jia Y, Juvik G, Roe T, Schroeder M, et al: SGD: Saccharomyces Genome Database. Nucleic Acids Res 1998, 26:73-79. 
69. Team RDC: R: A language and environment for statistical computing. Vienna, Austria: R Foundation for Statistical Computing; 2007.

70. Csardi G, Nepusz T: The igraph software package for complex network research. Int J Complex Syst 2006, 1695.

71. Lemos B, Bettencourt BR, Meiklejohn CD, Hartl DL: Evolution of proteins and gene expression levels are coupled in Drosophila and are independently associated with mRNA abundance, protein length, and number of protein-protein interactions. Mol Biol Evol 2005, 22:1345-1354.

72. Kim SH, Yi SV: Understanding relationship between sequence and functional evolution in yeast proteins. Genetica 2007, 131:151-156.

73. Mevik BH, Wehrens R: The pls package: Principal component and partial least squares regression in R. Journal of Statistical Software 2007, 18.

74. Brem RB, Kruglyak $L$ : The landscape of genetic complexity across 5,700 gene expression traits in yeast. Proc Natl Acad Sci USA 2005, 102:1572-1577

75. Gasch AP, Spellman PT, Kao CM, Carmel-Harel O, Eisen MB, Storz G, Botstein D, Brown PO: Genomic expression programs in the response of yeast cells to environmental changes. Mol Biol Cell 2000, 11:4241-4257.

76. Gasch AP, Huang M, Metzner S, Botstein D, Elledge SJ, Brown PO: Genomic expression responses to DNA-damaging agents and the regulatory role of the yeast ATR homolog Mec1p. Mol Biol Cell 2001, 12:2987-3003.

77. Hughes TR, Marton MJ, Jones AR, Roberts CJ, Stoughton R, Armour CD, Bennett HA, Coffey E, Dai H, He YD, et al: Functional discovery via a compendium of expression profiles. Cell 2000, 102:109-126.

78. Huisinga KL, Pugh BF: A TATA binding protein regulatory network that governs transcription complex assembly. Genome Biol 2007, 8:R46.

79. Mnaimneh S, Davierwala AP, Haynes J, Moffat J, Peng WT, Zhang W, Yang X, Pootoolal J, Chua G, Lopez A, et al: Exploration of essential gene functions via titratable promoter alleles. Cell 2004, 118:31-44.

80. O'Rourke SM, Herskowitz I: Unique and redundant roles for HOG MAPK pathway components as revealed by whole-genome expression analysis. Mol Biol Cell 2004, 15:532-542.

81. Roberts CJ, Nelson B, Marton MJ, Stoughton R, Meyer MR, Bennett HA He YD, Dai H, Walker WL, Hughes TR, et al: Signaling and circuitry of multiple MAPK pathways revealed by a matrix of global gene expression profiles. Science 2000, 287:873-880

82. Saldanha AJ, Brauer MJ, Botstein D: Nutritional homeostasis in batch and steady-state culture of yeast. Mol Biol Cell 2004, 15:4089-4104.

83. Spellman PT, Sherlock G, Zhang MQ, lyer VR, Anders K, Eisen MB, Brown PO, Botstein D, Futcher B: Comprehensive identification of cell cycleregulated genes of the yeast Saccharomyces cerevisiae by microarray hybridization. Mol Biol Cell 1998, 9:3273-3297.

84. The Yeast Functional Genomics Database. [http://yfgdb.princeton.edu/].

85. Troyanskaya O, Cantor M, Sherlock G, Brown P, Hastie T, Tibshirani R, Botstein D, Altman RB: Missing value estimation methods for DNA microarrays. Bioinformatics 2001, 17:520-525.

86. Lee HK, Hsu AK, Sajdak J, Qin J, Pavlidis P: Coexpression analysis of human genes across many microarray data sets. Genome Res 2004, 14:1085-1094.

87. Benjamini $Y$, Hochberg $Y$ : Controlling the false discovery rate: a practical and powerful approach to multiple testing. J R Statist Soc Ser B 1995, 57:289-300.

88. Zhu D, Hero AO, Qin ZS, Swaroop A: High throughput screening of coexpressed gene pairs with controlled false discovery rate (FDR) and minimum acceptable strength (MAS). J Comput Biol 2005, 12:1029-1045.

doi:10.1186/1752-0509-4-179

Cite this article as: Pang et al:: Understanding protein evolutionary rate by integrating gene co-expression with protein interactions. BMC

\section{Submit your next manuscript to BioMed Central and take full advantage of:}

- Convenient online submission

- Thorough peer review

- No space constraints or color figure charges

- Immediate publication on acceptance

- Inclusion in PubMed, CAS, Scopus and Google Scholar

- Research which is freely available for redistribution

Submit your manuscript at www.biomedcentral.com/submit 